\title{
Editorial
}

\section{Acessibilidade: pressuposto para o cuidado no âmbito da saúde do idoso com mobilidade reduzida}

\author{
Wiliam César Alves Machado*
}

Fundada em 1940, a Associação Brasileira de Normas Técnicas (ABNT) é o órgão responsável pela normatização técnica no país. A norma brasileira NBR 9050:2004 [1] institui parâmetros antropométricos para acessibilidade a edificações, mobiliário, espaços e equipamentos urbanos. Trata-se de um manual da ABNT que contém o conjunto de Normas Técnicas para acessibilidade de pessoas com mobilidade reduzida e/ou deficiência a edificaçôes, mobiliário e equipamentos urbanos. O manual é um instrumento de consulta obrigatória para arquitetos e engenheiros que se preocupam, em seus projetos, com a acessibilidade de todas as pessoas, independente da performance corporal/sensorial que apresentem. É também valioso, senão indispensável, para prefeituras, secretarias de obras, além de setores empresariais afetos ao planejamento e execução de projetos arquitetônicos para uso coletivo. $\mathrm{O}$ objetivo da norma é fixar padróes e critérios que visam proporcionar a todos condiçôes adequadas e seguras de acessibilidade autônoma a edificaçôes, espaços, equipamentos e mobiliário urbanos [2].

Quando aplicada ao universo de cuidados para com pessoas idosas e com limitaçóes funcionais, a concepção da acessibilidade deve manter-se indissociável do compromisso de os ambientes estarem adequados, adaptados e seguros, de modo que tanto cuidador como quem receba seus cuidados possam circular com autonomia e independência funcional, em suas instalações. Mesmo que os ambientes estejam acessíveis há que se valer da presença de um cuidador para auxiliar a pessoa idosa com mobilidade reduzida nas atividades da vida diária e autocuidado.

Nesse sentido, destaca-se que o bom cuidador [3] é aquele que observa e identifica o que a pessoa pode fazer por si, avalia as condiçóes e ajuda o idoso a realizar as atividades que não consiga executar sozinho. Cuidar não é fazer as coisas pelo outro, mas ajudá-lo quando ele necessita, estimulando-o a conquistar sua autonomia, mesmo que seja através do desempenho de pequenas tarefas. Cuidador é um ser humano de qualidades especiais, expressas pelo forte traço de amor à humanidade, de solidariedade e de doaçáo.

A ocupação de cuidador integra a Classificação Brasileira de Ocupaçóes - CBO [3:28], sob o código 5162, que define o cuidador como alguém que "cuida a partir dos objetivos estabelecidos por instituiçóes especializadas ou responsáveis diretos, zelando pelo bem-estar, saúde, alimentação, higiene pessoal, educação, cultura, recreação e lazer da pessoa assistida”. É a pessoa, da família ou da comunidade, que presta cuidados à outra pessoa de qualquer idade, que esteja necessitando de cuidados por estar acamada, com limitaçóes físicas ou mentais, com ou sem remuneração.

Mesmo no envelhecimento saudável, a partir dos 80 anos se espera algum grau de comprometimento fisiológico na capacidade de realização das atividades cotidianas. A intensidade e a freqüência deste comprometimento são muito variadas, dependendo das condiçóes gerais de saúde, ao

* Doutor em Ciências da Enfermagem pela UFRJ, Professor Adjunto da Universidade Federal do Estado do Rio de Janeiro, Secretário Municipal do Idoso e da Pessoa com Deficiência de Três Rios, Rio de Janeiro, Brasil 
longo da vida, e do modo de vida das pessoas em cada contexto sócio-econômico-histórico-cultural. Pautando-se no fato de que a capacidade funcional do ser humano declina com a idade, é necessário planejar estratégias que melhorem o estilo de vida dos idosos, principalmente em relação a programas que proporcionem: promoçáo e melhoria da força muscular e de articulaçáo; promoção, tratamento e reabilitação da capacidade funcional dos esfíncteres urinário e intestinal; integração social dentro e fora do contexto familiar; construção de um sistema adequado de suporte ao idoso; educação permanente ao longo da vida e valorização do processo de envelhecimento individual e populacional [4].

Indicadores sócio-demográficos divulgados pelo IBGE sobre perfil crescente da população brasileira de idosos requerem substantivas investidas das profissóes da área de saúde. Relevantes para a Enfermagem, área de conhecimento e prática social que, acima de tudo, carece do implemento de estratégias no ensino, pesquisa e âmbito assistencial, focadas na consciência cidadã pela resolubilidade e eliminação das barreiras que cerceiam direitos de seus clientes quanto ao acesso a serviços/cuidados com qualidade.

A acessibilidade ao meio físico promove a inclusão, a equiparação de oportunidades e o exercício da cidadania para todas as pessoas. Açóes que garantam a acessibilidade para pessoas com restrição de mobilidade aos serviços de saúde, sistemas de transportes, equipamentos urbanos e a circulação em áreas públicas são, nada mais, que o respeito de seus direitos fundamentais como indivíduos [5].

Dimensionada aos contextos institucionais e domiciliares do cuidado, acessibilidade implica conhecer para divulgar e compartilhar conhecimentos advindos da NBR 9050:2004. Sem domínio de seus meandros antropométricos e sua aplicação nos ambientes do cuidado, o enfermeiro e sua equipe ficam impedidos de oferecer o que a clientela idosa necessita em termos de bem-estar, conforto e segurança, além de se mostrarem sem parâmetros para orientar as famílias e/ou pessoas significativas quanto à adequação dos ambientes domiciliares.

Passados 20 anos da realizaçáo da I Assembléia Mundial do Envelhecimento, a Organização das Naçóes Unidas (ONU) realizou, de 08 a 12 de abril de 2002, em Madri, a II Assembléia Mundial do Envelhecimento, na qual foi aprovado o Plano Internacional sobre o Envelhecimento 2002. Tanto no primeiro como no segundo evento foi destacada como prioritária a aplicação da Declaração Universal dos Direitos Humanos, assim como a necessidade de inclusáo do idoso na vida social, cultural, econômica e política das sociedades [2].

Com efeito, a Sintese dos Indicadores Sociais do IBGE - 2003 [6] - assinala que havia 16.022.231 pessoas com 60 anos ou mais no país em 2002, representando $9,3 \%$ do total dos habitantes. A cada ano, mais de 600 mil pessoas ingressam nesse grupo etário, o que evidencia o dinamismo do envelhecimento no país. No ano 2020 espera-se que o número de pessoas acima de 60 anos atinja 25 milhóes e represente $11,4 \%$ do total dos brasileiros.

Diante do envelhecimento populacional, a meta no atendimento à saúde deixa de ser a de apenas prolongar a vida, mas, principalmente, a de manter a capacidade funcional do indivíduo, de forma que esse permaneça autônomo e independente pelo maior tempo possível. Para que isso ocorra, o sistema de saúde precisa garantir o acesso universal aos cuidados progressivos de saúde e as políticas públicas devem enfatizar a promoção de saúde e a prevençáo de doenças. Além disso, o idoso deve ser avaliado de acordo com a concepçáo holística, com o objetivo principal de manutenção da capacidade funcional [4].

Políticas de inclusão para as pessoas idosas tornam-se urgentes não somente no Brasil, como também nos demais países do mundo, ante o acelerado processo de envelhecimento da população, bem como diante de um cada vez maior índice de expectativa de vida em um mundo perplexo diante dos desafios do processo de globalização. No Brasil, segundo dados do Instituto Brasileiro de Geografia e Estatística, do ano de 2003, havia, aproximadamente, 16,4 milhóes de idosos, definidos como populaçáo de 60 anos e mais de idade. Esse número de idosos já correspondia a mais de 9,6\% da população brasileira [7].

Vale ressaltar que de acordo com a ONU [2], no século XX produziu-se uma revolução de longevidade. A expectativa média de vida ao nascer aumentou 20 anos desde 1950 e chega agora a 66 anos, e se prevê que até 2050 tenha aumentado mais 10 anos. Na Ásia e na América Latina, a proporção do grupo classificado como idosos aumen- 
tará de $8 \%$ para $15 \%$ entre 1998 e 2025 , ao passo que na África é previsto que esta proporção cresça somente de $5 \%$ a $6 \%$ durante esse período, e que depois se duplique até o ano de 2050. Na África subsahariana, onde continua a luta contra o vírus da AIDS e as dificuldades econômicas e sociais, o percentual chegará à metade desse nível. $\mathrm{Na}$ Europa e América do Norte, entre 1998 e 2025, a proporção da população classificada como pessoas idosas aumentará de $20 \%$ para $28 \%$ e de $16 \%$ para $26 \%$, respectivamente. Uma transformação demográfica mundial desse tipo tem profundas conseqüências para cada um dos aspectos da vida individual, comunitária, nacional e internacional. Todas as facetas da humanidade - sociais, econômicas, políticas, culturais, psicológicas e espirituais - experimentarão uma revolução.

Planejar cuidados para pessoas idosas implica, em primeira instância, na avaliação do grau de dependência das mesmas, em relação a ajuda do cuidador. Assim, a dependência pode ser considerada em três níveis: a dependência estruturada, resultante da circunstância cultural que atribui valor ao ser humano em função do que é e do quanto produz; a dependência física que decorre da incapacidade funcional, ou seja, a falta de condiçóes para realizar as tarefas da vida diária em diferentes graus de severidade e a dependência comportamental, que é socialmente induzida, pois advém do julgamento e das açôes de outrem. A dependência da pessoa idosa ocorre quando se torna incapaz de realizar as atividades $\mathrm{da}$ vida diária e, quando isso acontece, um cuidador assume a função de apoio, por meio do cuidado que pode ser permanente ou temporário. Tendo em vista que os cuidadores estão em condiçóes de sobrecarga de trabalho e vivenciam situaçóes de conflito em seu ambiente familiar que contribuem para o seu adoecimento, cabe aos profissionais de saúde propor políticas e implantar programas de suporte social à família, voltados para a realidade desses cuidadores [8].

Atender ao idoso de forma integral é preocupar-se náo apenas com todos os aspectos do processo saúde-doença que o mesmo enfrenta. É fundamental atendê-lo em suas necessidades físicas, sensoriais, emocionais, espirituais e sociais, integrando-os com outras pessoas, em especial outros indivíduos da mesma faixa etária que a sua, proporcionando-lhes atividades e ocupação.
Respeitar aos idosos, é respeitá-los em sua integralidade, proporcionar-lhes atividades culturais, de lazer e educativas; poderem ser transportados de um lugar a outro com segurança e conforto, para que exerçam seu direito à liberdade; desenvolver ambiente de convívio pacífico, sendo assegurados o bem-estar e a efetivaçáo do seu direito à vida [9].

No escopo do Ministério da Saúde, a finalidade primordial da Política Nacional de Saúde da Pessoa Idosa é recuperar, manter e promover a autonomia e a independência dos indivíduos idosos, direcionando medidas coletivas e individuais de saúde para esse fim, em consonância com os princípios e diretrizes do Sistema Único de Saúde. É alvo dessa política todo cidadão e cidadã brasileiros com 60 anos ou mais de idade [10]. Sabe-se que a legislação brasileira relativa aos cuidados da população idosa é bastante avançada, porém, a prática ainda é insatisfatória. A vigência do Estatuto do Idoso e seu uso como instrumento para a conquista de direitos dos idosos, a ampliação da Estratégia Saúde da Família que revela a presença de idosos e famílias frágeis e em situação de grande vulnerabilidade social e a inserção ainda incipiente das Redes Estaduais de Assistência à Saúde do Idoso tornaram imperiosa a readequação da Política Nacional de Saúde da Pessoa Idosa (PNSPI).

Não se pode perder de foco que o envelhecimento deve chegar naturalmente e com saúde, de forma ativa, livre de qualquer tipo de dependência funcional, o que exige promoçáo da saúde em todas as idades. Importante acrescentar que muitos idosos brasileiros envelheceram e envelhecem apesar da falta de recursos e da falta de cuidados específicos de promoção e de prevenção em saúde. Entre esses estáo os idosos que vivem abaixo da linha de pobreza, analfabetos, os sequelados de acidentes de trabalho, os amputados por arteriopatias, os hemiplégicos, os idosos com síndromes demenciais, e para eles também é preciso achar respostas e ter açóes específicas.

Isto posto, cumpre-nos - enfermeiros - a responsabilidade de agir no sentido de participar mais ativamente dos cursos para formação de cuidadores, particularmente, se engajados nas conjunturas universitárias de ensino, pesquisa e extensão, contribuindo na promoção da oferta de cuidados em nível de excelência para a crescente 
parcela de idosos da população brasileira. A evidente fragilidade estrutural dos serviços públicos de saúde em seus diversos níveis, a persistência nefasta do enfoque biomédico nos programas de ensino de Enfermagem, além das resistências ao novo da parte dos profissionais que atuam na área assistencial, não deve nos intimidar, tampouco ser motivo para que nos acomodemos. Não há mais tempo a perder, temos de acreditar e náo podemos duvidar do potencial de cada um de nós para reverter o statu quo, avançando rumo ao que nos tornará efetivamente referência qualitativa para a saúde da sociedade.

\section{Referências}

1. Associação Brasileira de Normas Técnicas. Acessibilidade a edificaçóes, mobiliário, espaços e equipamentos urbanos. NBR 9050:2004. Rio de Janeiro; 2004.

2. Organização das Naçóes Unidas. Plano de ação internacional contra o envelhecimento. Traduzido por: Arlene Santos. Brasília: Secretaria Especial dos Direitos Humanos: Brasília: 2007. 84 p.

3. Ministério da Saúde. Secretaria de Atenção à Saúde. Secretaria de Gestão do Trabalho e da Educação na
Saúde. Guia prático do cuidador. Brasília: Ministério da Saúde; 2008.

4. Costa EC, Nakatani AYK;, Bachion MM. Capacidade de idosos da comunidade para desenvolver atividades de vida diária e atividades instrumentais de vida diária. Acta Paul Enferm 2006;19(1):43-48.

5. Machado WCA. Vivências e deficiência - recortes da realidade: cotidiano dos conselhos municipais das pessoas com deficiência. Rio de Janeiro: Águia Dourada; 2008.

6. IBGE. Instituto Brasileiro de Geografia e Estatística. Síntese dos indicadores sociais 2003. IBGE: Brasília; 2004. 407p.

7. Brasil. Presidência da República. Subsecretaria de Direitos Humanos. Plano de Ação para o Enfrentamento da Violência Contra a Pessoa Idosa. Brasília; 2005.

8. Rocha MPF, Vieira MA, Sena RR. Desvelando o cotidiano dos cuidadores informais de idosos. Rev Bras Enferm 2008;61(6):801-8.

9. Martins MS, Massarollo MCKB. Mudanças na assistência ao idoso após promulgação do Estatuto do Idoso segundo profissionais de hospital geriátrico. Rev Esc Enferm USP 2008;42(1):26-33.

10. Ministério da Saúde. Portaria no 2.528 de 19 de outubro de 2006. Aprova a Política Nacional de Saúde da Pessoa Idosa. Brasília: Ministério da Saúde; 2006. 